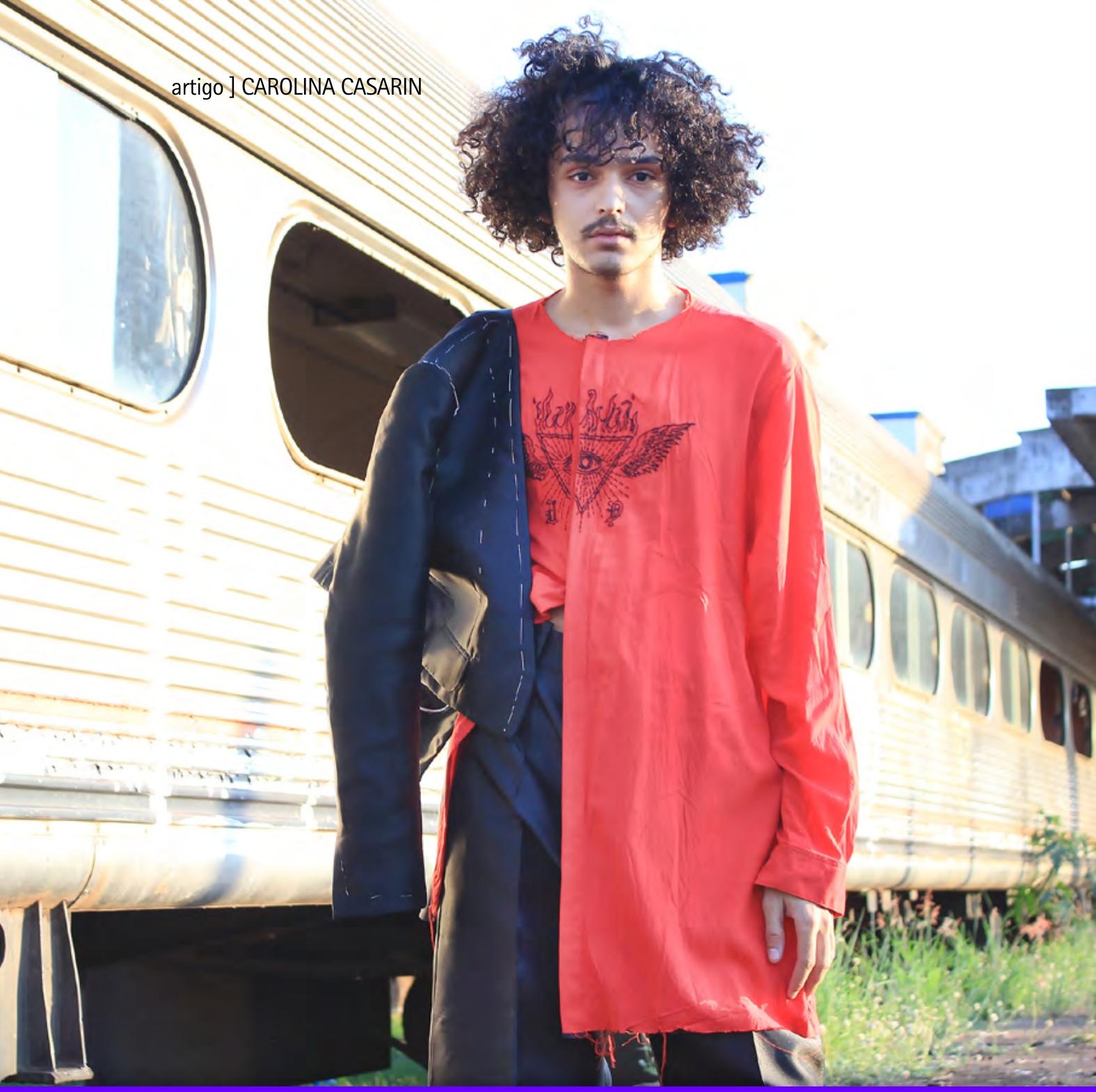

\title{
Os modernistas e as roupas
}

The modernists and the clothes 


\section{[CAROLINA CASARIN]}

Doutoranda no Programa de Pós-graduação em Artes

Visuais da Escola de Belas Artes da UFRJ.

E-mail: carolinacasarin7@gmail.com

[resumo] Este artigo faz parte da pesquisa de doutorado 0 guarda-roupa modernista, em que são analisados os trajes e a aparência de Mário de Andrade, Tarsila do Amaral e Oswald de Andrade. Compara-se a aparência e o vestuário desses artistas com o projeto estético e ideológico do modernismo brasileiro - aquele engendrado pelos modernistas de São Paulo -, marcado pelo desejo, sobretudo a partir de meados da década de 1920, de elaboração de uma identidade nacional. Neste texto, a interpretação está voltada para alguns registros de roupas usadas por Mário de Andrade e Oswald de Andrade. Procura-se relacionar os modos de vestir dos dois poetas com o projeto de brasilidade modernista.

[palavras-chave]

modernismo brasileiro, brasilidade, aparência, vestuário, práticas vestimentares.

[abstract] This article is part of the doctoral research The Modernist Wardrobe, which analyses the costumes and the appearance of Mário de Andrade, Tarsila do Amaral and Oswald de Andrade. The appearance and the clothing of these artists is compared with the aesthetic and ideological design of Brazilian modernism - that engendered by the modernists of São Paulo -, marked by the desire, especially since the mid-1920s, for the elaboration of a national identity. In this text, the interpretation is directed to some pictures of clothes used by Mário de Andrade and Oswald de Andrade. We tried to relate the ways of dressing of these two poets with the modernist Brazilianism project.

[keywords] Brazilian modernism, Brazilianism, appearance, clothing, dressing practices. 


\section{O guarda-roupa modernista}

Este texto faz parte da pesquisa de doutorado 0 guarda-roupa modernista: aparência e vestuário de Mário de Andrade, Tarsila do Amaral e Oswald de Andrade, em que procuro compor os trajes e a aparência' de três dos principais artistas da primeira geração do modernismo brasileiro ${ }^{2}$, por meio de um corpus diverso. Relaciono o vestuário e a visualidade ${ }^{3}$ de Mário de Andrade, Tarsila do Amaral e Oswald de Andrade 4 com o projeto estético e ideológico que esses intelectuais ajudaram a elaborar, marcado pelo desejo de atualização em relação às vanguardas europeias e, sobretudo a partir de 1924, pelo engajamento num projeto de brasilidade que consistiu, também, na construção de uma imagem de Brasil.

Os trajes podem ser compreendidos como fontes importantes que contribuem para o entendimento da realidade social em que vivemos. $\mathrm{Na}$ medida em que os modernistas iam construindo uma imagem de si e do Brasil, e, depois, nas apropriações que foram feitas das obras e da história do modernismo, nos desdobramentos culturais, artísticos e políticos que 0 movimento acabou por engendrar, o traje é um recurso de criação de uma identidade visivel que, com a passagem do tempo, acaba por se expressar por meio de imagens. Sendo a elaboração da identidade nacional uma parte importante do projeto dos modernistas, são observados os registros das roupas usadas por Mário de Andrade, Tarsila do Amaral e Oswald de Andrade, considerando o contexto estético, histórico e social de suas escoIhas vestimentares ${ }^{5}$.

0 guarda-roupa modernista é a visão em conjunto dos registros dos trajes destes três artistas. Dei-me a função de montar o guarda-roupa $\mathrm{e}_{\text {, }}$ ao mesmo tempo, analisá-lo, sabendo que a composição em si do guarda-roupa, a ação de montá-lo, já é o resultado de uma interpretação.

A palavra "guarda-roupa" data do século XIV e tem diferentes significados que transitam entre objeto, função e conjunto. No seu sentido mais objetivo, o guarda-roupa é um objeto de mobiliário, um armário destinado a acondicionar roupas. Designa também uma função, ou seja, é uma pessoa responsável por cuidar dos figurinos de uma instituição, um teatro, uma companhia teatral, uma produtora de cinema ou de TV etc. No Brasil Colônia e Império, o guarda-roupa era aquele que guardava as roupas dos fidalgos, pessoa que tinha à sua conta a roupa de outrem, e, mais tarde, tornou-se um dos cargos da corte imperial brasileira. Quando compreendi- 
da no sentido de conjunto, a palavra guarda-roupa significa um conjunto de trajes, a reunião do vestuário de um indivíduo ou de um grupo ${ }^{6}$.

A palavra "guarda-roupa" é aqui utilizada no duplo sentido: conjunto e função. A reunião dos trajes usados por Mário de Andrade, Tarsila do Amaral e Oswald de Andrade; e, naquele registro antigo em língua portuguesa, do sujeito que cuida das roupas de outrem. 0 guarda-roupa modernista é colocado em cena, discursivamente, na medida em que são reunidas inúmeras referências, antes dispersas, num só espaço (mesmo que seja no espaço da escrita). Além disso, a expressão "guarda-roupa modernista" se refere tanto ao conjunto dos trajes que pertenceram ao trio, quanto àquilo que, no contexto do modernismo brasileiro, pode ser considerado como índice de modernidade no vestuário desses artistas.

0 vestuário é um objeto de pesquisa intimamente relacionado ao corpo, na medida em que parte do corpo e tem no corpo sua premissa. Olivier Burgelin (1995), autor do verbete "Vestuário" na Enciclopédia Einaudi, afirma que na origem do ato de vestir estão atreladas as necessidades práticas às mágicas. Burgelin sublinha, assim, o vínculo entre magia e estética que estaria na base da criação do vestuário, ressaltando seu caráter expressivo: "a necessidade de manifestar um significado" (BURGELIN, 1995, p. 338). Magia e ornamentação, magia e estética estão, assim, primitivamente associadas. Mas o vestuário, acrescenta Olivier Burgelin, "não se destina apenas a ser usado por um corpo humano com o qual estabelece intimas relações ao mesmo tempo plásticas e investidas de afetividade; aparece também num certo contexto onde deve inserir-se" (BURGELIN, 1995, p. 342). 0 vestuário é, portanto, uma forma que responde à necessidade básica de expressão do corpo, que, uma vez materializada, acaba por ser inserida num contexto.

A cultura material possibilita a compreensão de uma série de fatores ligados à história da humanidade: "a partir dos objetos pode-se compreender como são feitos, para que são usados, como se dá a circulação dos materiais e modelos e quais são os seus valores expressivos em termos culturais e estéticos" (VOLPI, 2013, p. 2). As roupas são, portanto, documentos da história, especialmente das pequenas histórias, da narrativa de cada corpo. Os objetos de vestuário fazem parte de uma ordem de reminiscências que colaboram no esforço de articulação histórica do passado, isto é, no esforço de deslindar os significados culturais e sociais que sustentam 0 passado e, não raras vezes, explicam criticamente o presente. Ao mesmo tempo em que as roupas expressam construções individuais, elas revelam usos coletivos, padronizados pelas relações sociais, de poder, pelas condições climáticas, por gênero, e até mesmo por idade: são diversas as marcas de coletividade impressas no vestuário. 
De modo geral, o estudo do vestuário está pautado na materialidade dos objetos das coleções de museus e acervos de indumentária. Porém, quando são poucas as peças de vestuário conservadas, como é o caso desta pesquisa, revela-se um interessante ponto de discussão metodológica, pois o acesso ao vestuário se dá por meio de fontes variadas. Os registros das peças trajadas por Mário de Andrade, Tarsila do Amaral e Oswald de Andrade configura um corpus de análise que é material, visual e discursivo. Fotografias, desenhos, obras de arte, cartas, crônicas, poemas, diários, recortes de jornais, depoimentos, enfim, os diversos tipos de vestígio dos trajes. Inúmeros documentos sob a guarda de diferentes instituições brasileiras ${ }^{7}$ revelam fotografias das temporadas no campo, das viagens - pelo Brasil e internacionais -, de almoços e jantares; periódicos que cobriam os eventos sociais; autorretratos; correspondências; caricaturas; crônicas e diários; depoimentos sobre o grupo; e ainda recibos, pedaços de tecido, croquis, objetos de vestuário, poucas peças de roupa.

A interpretação do guarda-roupa modernista se pauta num método que articula tipos variados de fontes. De acordo com Maria Cristina Volpi, o historiador do vestuário deve

problematizar uma nova tipologia de fontes iconográficas (pinturas, estampas, gravuras e fotografias) associando-as aos documentos de arquivo (de notários, comerciantes, fabricantes e famílias) e aos trajes. [...] 0 emprego desses diversos tipos de fontes revela formas e práticas vestimentares, contribuindo para a apreensão dos aspectos simbólicos do uso, sendo úteis, em muitos casos, para se conhecer a prática vestimentar efetiva, evidenciando o contexto no qual a aparência foi produzida (VOLPI, 2013, p. 1-2).

Dentre as peças de vestuário de Mário de Andrade, Tarsila do Amaral e Oswald de Andrade que foram preservadas, estão o traje de noiva usado por Tarsila em seu casamento com Oswald (feito por Paul Poiret ${ }^{8}$, a pedido do escritor, a partir do vestido de casamento de sua mãe, e que está sob a guarda da Pinacoteca do Estado de São Paulo), e acessórios que foram de Mário de Andrade, como alguns chapéus de palha, provavelmente recolhidos ao longo de suas viagens ao Norte e ao Nordeste do Brasil (que estão na Coleção de Artes Visuais do Instituto de Estudos Brasileiros da USP), e seus óculos de aro de ouro 18 quilates, expostos na Casa Mário de Andrade.

Em consequência da pouca quantidade de fontes primárias materiais, que seriam os objetos de vestuário - sem ignorar o caráter material que pinturas, desenhos e fotografias também apresentam, já que são artefatos -, a composição do guarda-roupa modernista, ou seja, a reunião do conjunto dos trajes que pertenceram ao trio 
de artistas, parte majoritariamente de um material de análise que é visual e escrito.

No livro Sistema da moda (2009), Roland Barthes estabelece três tipos de vestuário: o vestuário-imagem, o escrito e o real. Os dois primeiros remetem ao vestuário real. Remetem, são equivalentes, mas não idênticos, como adverte 0 autor (BARTHES, 2009, p. 21). Estamos lidando com três estruturas e matérias diferentes. A estrutura plástica, das formas, no vestuário-imagem; a verbal, discursiva, no escrito; e a tecnológica no vestuário real, "uma estrutura que se constitui no nível da matéria e de suas transformações, e não de suas representações ou de suas significações" (BARTHES, 2009, p. 22).

Os registros visuais e escritos do vestuário e da aparência desses modernistas são capazes de fornecer vestígios, resíduos, um tipo de memória da relação que um dia se estabeleceu entre aqueles corpos e as roupas que os vestiram. Certamente, parte dessa memória está impressa nas imagens e nos discursos. Como dito anteriormente, analisar o guarda-roupa modernista é exercer a função de guarda-roupa, na medida em que recolho os vestígios e as imagens das roupas, agrupando-os e dando-lhes um sentido. Revelar as práticas vestimentares de Mário de Andrade, Tarsila do Amaral e Oswald de Andrade, é lidar com corpos de pessoas cujas existências agora são objeto de análise. Produzir um saber científico a partir da vida de pessoas exige um senso de responsabilidade e cuidado com as narrativas que são fruto dessa pesquisa. 0 desenvolvimento do trabalho aponta, então, para a necessidade de um mediador teórico, um dispositivo que auxilia a mediação entre o corpus da tese, as fontes de pesquisa e a narrativa que está sendo construída por meio da análise das fontes. A obra Fragmentos de um discurso amoroso, de Roland Barthes (2003), propõe o termo "figuras", compreendido como um conceito.

Logo na introdução, chamada "Como é feito este livro", Roland Barthes esclarece o lugar de onde fala o sujeito amoroso: "oferece à leitura um lugar de palavra, o lugar de alguém que fala em si mesmo, amorosamente, em face do outro (o objeto amado), que não fala" (BARTHES, 2003, p. XVII). Em seguida, 0 autor define de que são feitos os fragmentos: de figuras, no sentido de "um gesto apanhado em ação, e não contemplado em repouso" (Barthes, 2003, p. XVIII). E Barthes continua:

As figuras se destacam segundo possamos reconhecer, no discurso que está passando, alguma coisa que foi lida, ouvida, experimentada. A figura é delineada (como um signo) e memorável (como uma imagem ou um conto). Uma figura é fundada se ao menos alguém puder dizer: "Como isso é verdade! Reconheço 
esta cena de linguagem." Para certas operações de sua arte, os lingüistas recorrem a uma coisa vaga: o sentimento lingüístico; para constituir figuras, é preciso nem mais nem menos do que este guia: o sentimento amoroso (BARTHES, 2003, p. XVIII, grifos no original).

0 método do discurso amoroso, tal como o apresenta Roland Barthes, é aquele que engendra uma fala ensimesmada porque parte de um outro que não fala. A fala do discurso amoroso cria figuras que têm a consistência de um signo e a força de uma imagem. A criação das figuras pressupõe ainda o reconhecimento do outro, quer dizer, pressupõe que exista uma visualidade que seja minimamente reconhecivel pela sociedade. 0 sujeito do discurso amoroso fala em face de um outro que não fala. Mas, é a mudez do objeto amado que provoca o discurso amoroso. Afirma-se a potência das imagens, que funcionam como agentes: "quando vemos o que está diante de nós, por que uma outra coisa sempre nos olha, impondo um em, um dentro?", pergunta-se Georges Didi-Huberman (2014, p. 30). A figura, portanto, só existe se provocar em alguém o reconhecimento.

A definição conceitual de figura proposta por Roland Barthes e mencionada logo antes - "um gesto apanhado em ação, e não contemplado em repouso" -, relaciona-se com a maneira pela qual Gilda de Mello e Souza compreende a vestimenta como uma arte:

Assim como para julgarmos a beleza de um rosto não podemos separar o acordo das linhas da expressão que as anima - tantos rostos sendo belos por possuírem exatamente essa beleza de expressão -, para que a vestimenta exista como arte é necessário que entre ela e a pessoa humana se estabeleça aquele elo de identidade e concordância que é a essência da elegância. Recompondo-se a cada momento, jogando com o imprevisto, dependendo do gesto, é a moda a mais viva, a mais humana das artes. [...] 0 vestido que escolhemos atentamente na modista ou no magasin bon marché não tem moldura alguma que o contenha e nós completamos com 0 corpo, o colorido, os gestos, a obra que o artista nos confiou inacabada (SOUZA, 2005, p. 41).

É no gesto, na ação, que o vestuário acontece. As imagens de Mário de Andrade, Tarsila do Amaral e Oswald de Andrade fixadas nos retratos e nas fotografias tornam-se figuras na medida em que são relacionadas aos discursos que as atravessam. Para que o registro ganhe vida, é necessário contextualizar a presença dos três no espaço histórico-social e artístico que engendrou seus trajes, analisando as relações que esses modernistas 
estabeleceram, por meio de suas pessoas, suas aparências, suas roupas, com os ambientes que frequentavam. " 0 significado social que o traje adquire se expressa através de sua estética e, ao mesmo tempo, revela a ligação intelectual e afetiva que se estabelece entre o traje e seu usuário", afirma Maria Cristina Volpi (VOLPI, 2013, p. 9).

Se as escolhas pessoais que compõem um guarda-roupa são também um modo singular de elaboração da identidade, e o projeto de modernismo brasileiro capitaneado por Mário de Andrade, Tarsila do Amaral e Oswald de Andrade na década de 1920 foi coletivo e individual, a construção de uma imagem de Brasil passa pela elaboração de uma imagem de si, de uma aparência. De acordo com Michèle Pagés-Delon, a aparência corporal é

entendida como o corpo e os objetos que ele usa, o corpo, sua apresentação, sua representação, quer dizer, o conjunto das características físicas constantes ou que variam lentamente (peso, altura, traços do rosto), de atitudes corporais (posturas, expressões, imitações) e de atributos (roupas, penteados, maquiagens, acessórios). [...] Toda interação social é, em primeiro lugar, corporal e regida por uma série de rituais que, tendo sempre o corpo como suporte, formam a trama do viver junto, da sociabilidade (PAGÉS-DELON, 1989, p. 9-10)9.

Corpo, vestuário e aparência fazem parte da trama do viver junto. "Índices de uma condição social determinada pelas informações que elas revelam", continua Michèle Pagés-Delon, "as aparências corporais são construídas por toda uma série de práticas e representações" (1989, p. $12)^{10}$. E a autora completa:

práticas [são] um conjunto de atividades, condutas, ações que colocam em cena um determinado número de meios, ferramentas e técnicas e visam uma ou algumas finalidades particulares. As aparências corporais são o resultado da produção de uma combinação de práticas: vestimentares, de higiene, esportivas ou para-esportivas, alimentares, de inscrição e de apresentação (PAGÉS-DELON, 1989, p. 12) ${ }^{11}$.

Assim, a interpretação do guarda-roupa modernista, pautada nos registros dos gestos e do vestuário de Mário de Andrade, Tarsila do Amaral e Oswald de Andrade, estende-se até o domínio da composição da aparência, das negociações feitas por essas três figuras na construção de suas personas de artistas brasileiros e modernos. 


\section{Brasilidade}

É notória a atenção que os três artistas dedicaram à aparência e ao vestuário. Para que sejam ressaltados o valor que atribuiam às roupas e a importância de suas estratégias de autorrepresentação, lembro que 0 casal Tarsiwald - como Mário de Andrade apelidou Tarsila do Amaral e Oswald de Andrade - nos anos 1920, em Paris, frequentou maisons de costureiros famosos, como Paul Poiret; vale a pena lembrar também Antonio Candido na "Digressão sentimental sobre Oswald de Andrade", ao mencionar as "luvas de palhaço" usadas pelo poeta, que tanto irritavam a burguesia paulistana:

Mas esse Oswald lendário e anedótico tem razão de ser: a sua elaboração pelo público manifesta o que o mundo burguês de uma cidade provinciana enxergava de perigoso e negativo para os seus valores artísticos e sociais. Ele escandalizava pelo fato de existir, porque a sua personalidade excepcionalmente poderosa atulhava o meio com a simples presença. Conheci muito senhor bem posto que se irritava só de vê-lo, como se andando pela rua Barão de Itapetininga ele pusesse em risco a normalidade dos negócios ou o decoro do finado chá-das-cinco. "Esse sujeito não tem pescoço, tem cachaço"12, ouvi de um, que parecia simplesmente tomado pela necessidade de dizer qualquer coisa desagradável. "Que luvas de palhaço!", dizia outro. Eram as que punha de vez em quando, penso que feitas para esporte de inverno, de tricô, brancas com uns motivos pretos vistosos. "Foi Blaise Cendrars quem me deu", disse ele sorrindo certa vez, na Livraria Jaraguá, onde passava sempre (CANDIDO, 2004, p. 48).

A roupa esportiva é fundamental para compreendermos a gradativa modernização e consequente informalização que ocorre no vestuário masculino durante a primeira metade do século $X X$, culminando com a chamada "revolução do pavão" na década de 1960. Em artigo publicado no livro Histórias do vestir masculino, Maria Cristina Volpi ressalta que no Brasil, após a Primeira Guerra Mundial, o modelo americano do homem racional e prático seria incluído na norma do vestir masculino, "trazendo consigo um novo padrão masculino: o desportista-empresário, homem descontraído, moderno e prático" (VOLPI, 2017, p. 32).

Por conta de sua posição social, é certo que Oswald de Andrade conhecia as normas burguesas do vestir masculino. Ao usar as luvas de esporte de inverno, luvas brancas de tricô que com certeza destoavam do padrão burguês da provinciana São Paulo nas primeiras décadas do século XX cuja norma vestimentar prescrevia luvas de couro ou pelica para o dia, nas cores bronze, cinza ou preto ${ }^{13}$-, Oswald de Andrade expressa, num só gesto, seu gosto por um tipo de roupa moderna; sua irreverência em relação à 
"normalidade dos negócios ou o decoro do chá-das-cinco"; seu desejo de provocar abalo nos senhores bem postos que se irritavam só de vê-lo, como afirma Antonio Candido; e o poder de sua personalidade.

Também em Mário de Andrade o interesse pelo vestuário e o modo particular e original de usar as próprias roupas são evidentes. Eles aparecem nas inúmeras referências à indumentária que constam em sua obra literária; nos croquis presentes no arquivo Mário de Andrade do IEB, dentre eles o desenho de um robe de chambre (documento MA-DP-096), feito pelo poeta, com especificações de tecido (satin brillant), detalhes ("o cinto é de satin brillant por dentro e com debrum dele por fóra") e acabamentos ("os riscos a tinta são costuras que aparecem"); nos depoimentos de pessoas próximas ao escritor, como aqueles de Gilda de Mello e Souza e José Bento Faria Ferraz. Começo pelas palavras de Zé Bento, "professor, escritor e pesquisador, secretário de Mário de Andrade de 1939 a 1945" (LOPEZ, 2008, p. 63):

Eu chegava cedo na casa do Mário, às sete e meia. Ele já estava com aquele robe de chambre de seda, azul, muito chique. Suas roupas todas eram assim, refinadas. 0 sapato era sob medida, encomendado na casa Guarani, na rua XV de Novembro. Sapato bico fino. Ele guardava os sapatos com fôrmas de madeira dentro, para manter sempre a forma certinha ${ }^{14}$. Preocupava-se com a elegância e era metódico por excelência (citado em LOPEZ, 2008, p. 65).

0 robe de chambre é um confortável traje caseiro que remonta aos séculos XVII e XVIII. Nessa época, o robe de chambre, usado por homens e mulheres da corte francesa, era um vestido diferente do vestido de corte, cujo uso era admitido nos quartos (chambre) dos aposentos reais, em situações que não fossem recepções e cerimônias. No decorrer do século XX, os robes de chambre destinaram-se ao uso em casa, em vez de apenas no quarto ou nos aposentos intimos. Chamado déshabillé ou negligé pelos franceses, esse traje caseiro, que também pode ser chamado de traje de interior, é uma peça usada entre trocas de roupas ou sobre a roupa de baixo. A origem do robe de chambre é a forma do quimono oriental. É uma peça folgada, de mangas compridas, feita de tecido leve e luxuoso e com bolsos chapados (ou seja, não são bolsos embutidos, são costurados por fora da roupa, como aquele proposto no croqui de Mário de Andrade). Normalmente tem modelagem transpassada e é amarrado na cintura. Ao longo da primeira metade do século $\mathrm{XX}$, apesar de ter gradativamente caído em desuso pelos homens, os robes de chambre masculinos mantiveram seu estilo clássico: são de seda ou de flanela e têm o comprimento na altura do tornozelo. Eram usados para a toalete da manhã e o café da manhã ${ }^{15}$. 
Figura 1: 0 croqui de robe de chambre feito por Mário de Andrade e uma fotografia do poeta em 1935 vestindo, provavelmente, uma de suas criações. Mário também desenhou móveis modernos para sua casa, como estantes e o sofá que podemos ver na fotografia.

(..) me sinto numa felicidade prodigiosa. Primeiro, pôr em dia a correspondência quanto puder, ou quanto quiser, boje não faço nada obrigado.

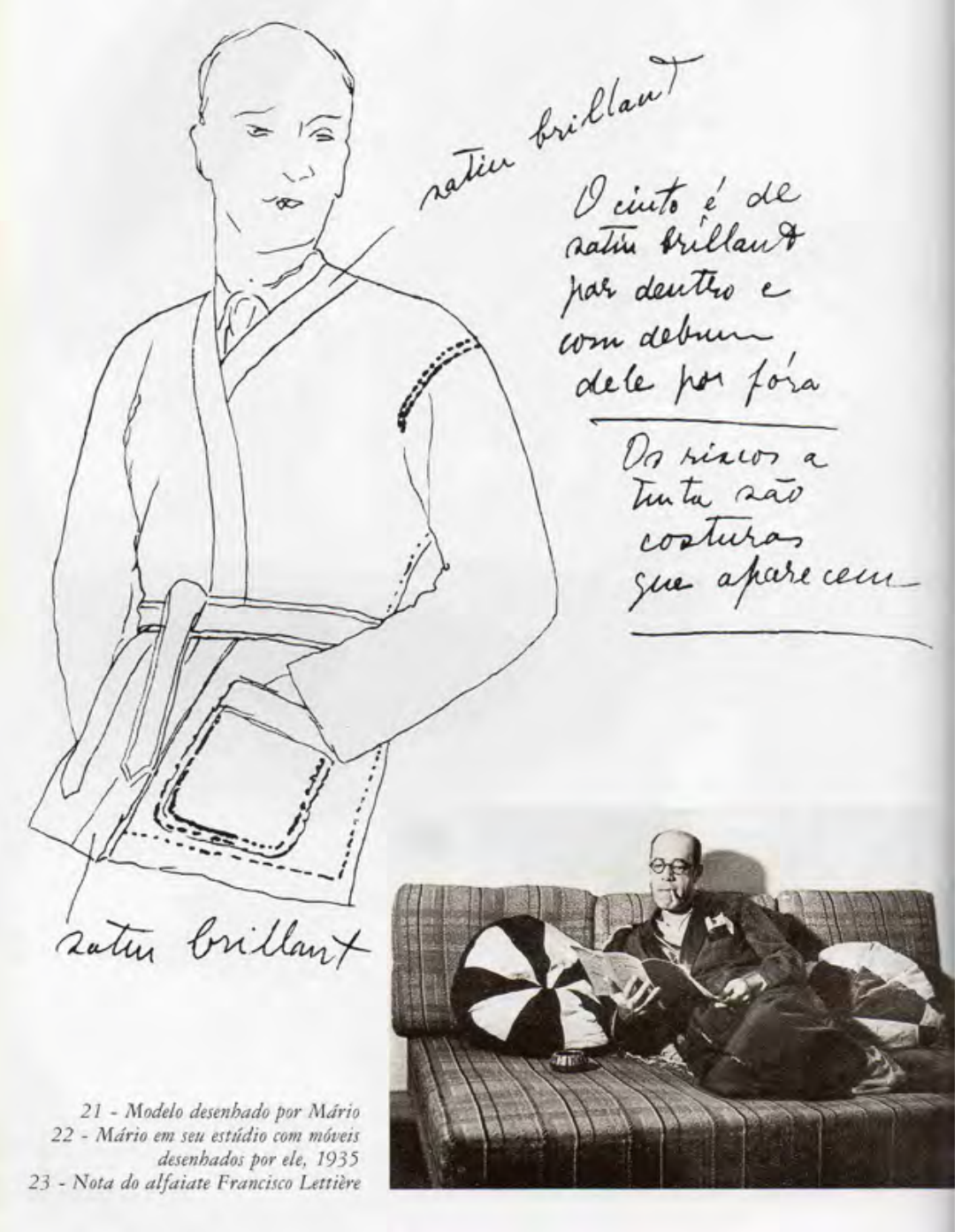

Fonte: imagem digitalizada da página 48 do livro A imagem de Mário:fotobiografia de Mário de Andrade (ANDRADE, M., 1998).

Os sapatos de Mário de Andrade e seu modo de vestir os trajes caseiros também aparecem no depoimento de Gilda de Mello e Souza sobre o escritor, que era seu parente ${ }^{16}$. Em agosto de 1992, no Centro Cultural São Paulo, a autora de 0 espirito das roupas falou sobre Mário de Andrade ${ }^{17}$, procurando dar seu testemunho sobre o poeta a partir de um ponto de vista de alguém que o conhecera intimamente e tivera "a chance enorme de vê-lo por um prisma diferente do convencional" (SOUZA, 1992). E continua: 
E talvez por isso mesmo contribua um pouco para que no futuro se possa desenhar o seu perfil, um perfil retificado pela visão intima de uma pessoa que já tem o seu perfil oficial perfeitamente delineado. Eu escolhi, talvez, uma maneira de me lembrar dele que fosse só minha, que ninguém pudesse se lembrar como eu me lembro, uma maneira de lembrar em que a única testemunha tenha sido eu e meus irmãos, por exemplo. E ela começa, portanto, na infância. Ela começa na infância e a primeira maneira que eu tenho de ver Mário, é curioso, é pelos sapatos. Acho que foi a primeira coisa que eu vi, não só porque ele era muito grande e o pé era enorme, e eu era muito pequenininha, tinha três ou quatro anos nessa ocasião, mas o sapato dele me impressionava enormemente porque era tão diferente do sapato do meu pai. Era um sapato enorme, um sapato castanho, em geral, e um sapato bordado. Era um sapato que ele comprava no Guarani. E aquilo era uma coisa fascinante pra mim, não só porque eu via primeiro o sapato, mas porque ele nos punha montado no sapato (SOUZA, 1992).

De novo, os calçados da sapataria Guarani comparecem como uma marca da elegância de Mário de Andrade, que era um sujeito alto, tinha um metro e noventa de altura. 0 sapato castanho e bordado, sapatos feitos à moda dos brogues escoceses e irlandeses ${ }^{18}$, devia mesmo contrastar com os calçados do pai de Gilda de Mello e Souza, provavelmente sóbrias botas de fazendeiro. E que espetáculo de diversão e beleza os sapatos do tio Mário foram para a pequena Gilda, que se tornaria uma das pioneiras do estudo sobre o vestuário e a moda no Brasil. Mais adiante, Gilda de Mello e Souza menciona os paletós de seda listada, usados em casa, feitos pela mãe de Mário:

E uma coisa que, nos dias que ele descia pra qualquer pessoa que chegasse, muitas vezes ele descia, era uma coisa que me impressionava, com um paletó de seda que minha avó [dona Maria Luísa, mãe de Mário] fazia pra ele, que era um paletó em geral de seda muito bonita, listada, que ele punha em vez do paletó. Ele, quando chegava do conservatório, tirava, em geral se era verão, o paletó da rua e botava um paletó desses de seda. E ele às vezes tinha um sobressalente pra visita. Eu me lembro perfeitamente de uma noite que o Manuel Bandeira jantou em casa, lá em casa dele, e que era muito quente, era uma noite muito quente, e ele fez o Manuel Bandeira tirar o casaco, subiu e trouxe um paletó de seda para o Manuel. E Manuel achou divertidissimo ficar com aquele paletó de seda (SOUZA, 1992).

0 paletó de seda listada usado em casa, apesar de não ser um déshabillé como o robe de chambre, é um tipo de traje caseiro adequado ao clima tropical e, por isso, mais confortável. É interessante porque, ainda de 
acordo com Gilda de Mello e Souza (1992), "a busca de identidade é uma dominante constante na obra de Mário e no comportamento dele de todo dia". 0 uso do paletó de seda listada em casa, nos dias quentes, é um exemplo do "código de valores", nas palavras de Gilda de Mello e Souza, forjado no desejo de busca e ao mesmo tempo criação da identidade brasileira, que não está separado da procura da própria identidade.

E, a essa busca da sua própria identidade, nós podemos acrescentar a busca da identidade de seu país. São duas coisas completamente paralelas que se cruzam a todo momento na obra, a todo momento na sua vida, é esta busca paralela da identidade do Brasil e da identidade dele mesmo. A ponto dele, a partir de um certo momento, construir todo um código em que os valores, os sinais valem para os dois. Valem para o Brasil e valem pra ele. Isso é uma das coisas mais ricas da poesia dele, é este paralelismo entre as duas identidades (SOUZA, 1992).

A entrega de Mário de Andrade, e também de Tarsila do Amaral e Oswald de Andrade, ao projeto de interpretação e construção da identidade brasileira é evidente. Não está fixada apenas nas obras de cada uma dessas figuras. 0 limite entre os corpos e as obras, entre as performances artísticas e as existenciais é tênue. Os modos de vestir, ou seja, a maneira como esses artistas se relacionam com o vestuário e a moda, e o modo como construíram suas aparências são relevantes para o entendimento do projeto de brasilidade desses modernistas e, também, para uma compreensão mais profunda e sistemática da história do vestuário no Brasil.

0 modernismo brasileiro teve duas orientações distintas, ainda que complementares (JARDIM, 2016). Num primeiro momento, de 1917 a 1924, a ação principal do movimento foi estabelecer uma guinada na produção artística brasileira, procurando atualizá-la em relação ao que se fazia na Europa e criticando duramente o tipo de literatura e arte que se fazia no Brasil, atrelada, nos dois campos, a um excesso de academicismo. A partir de meados da década de 1920, a questão da brasilidade ganha força, tornando-se o horizonte da intervenção de nossos principais artistas, e o projeto estético de Mário de Andrade, Tarsila do Amaral e Oswald de Andrade se volta para a pesquisa e a construção de uma identidade nacional. Por mais que as ideias de Mário e Oswald nem sempre concordem em referência à realização do projeto de brasilidade e às práticas artísticas que ele compreende, o desejo de criar uma alma brasileira está manifestado na literatura, nas artes plásticas, na música, e também nos modos de ser, nas relações sociais, na comida, na indumentária, amalgamando modernidade e brasilidade.

É possivel localizar o ano de 1924 como aquele que, na história do movimento modernista, marca uma alteração na postura de parte do grupo, 
que passa a incluir em suas produções artísticas a investigação de um sentido de Brasil. 0 grupo modernista, em especial Mário de Andrade, Tarsila do Amaral e Oswald de Andrade, volta-se para o interior do Brasil, aquilo que consideravam nossas raizes históricas, no intuito de fortalecer valores na busca de uma identidade nacional, que fosse, em todos os sentidos, mais brasileira. Sobre a mudança de postura do grupo modernista de São Paulo a partir de 1924, afirma Telê Porto Ancona Lopez:

Reconhecendo a alienação vinda da moda da cultura francesa e de toda uma civilização moldada à européia, o Modernismo estará, em 1924, tentando filtrar dialeticamente as vanguardas européias e, na exploração do primitivismo, partir para a descoberta vivida do Brasil. [...] A "Viagem da descoberta do Brasil" provoca um amadurecimento no projeto nacionalista de nossos modernistas, fazendo com que a ênfase, que de início recairá com mais força sobre o dado estético, possa ir, progressivamente, abrangendo e sulcando o projeto ideológico. Assim, surge Pau Brasil, um programa explícito, e a poesia de Mário de Andrade em Clã do Jaboti transformará em prática culta a validade estética ou técnica de soluções populares, iluminada por uma consciência de Brasil que se propõe crítica dentro da "poesia de circunstância" (LOPEZ, 2002, p. 15-16).

A "viagem da descoberta do Brasil" a que se refere Telê Ancona Lopez é a viagem que Mário de Andrade, Tarsila do Amaral, Oswald de Andrade, Nonê (filho de Oswald), Olivia Guedes Penteado, Goffredo da Silva Telles (genro de Olívia), e o poeta franco-suiço Blaise Cendrars fizeram às cidades históricas de Minas Gerais. Conhecida como a "caravana paulista", "que andava descobrindo o Brasil depois do Carnaval passado no Rio de Janeiro" (NAVA, 2013, p. 504), o grupo entraria em Minas "por São João del Rei e sairia por Congonhas do Campo. Belo Horizonte estava no itinerário" (NAVA, 2013, p. 504-505). Carlos Drummond de Andrade ${ }^{19}$ lembra, em crônica publicada na edição de 22 de maio de 1968 do Correio da Manhã o encontro com o grupo modernista, e descreve a sensação de conhecer Mário de Andrade pessoalmente, o impacto de sua presença corporal:

Já não lembro do que falamos: de tudo. As respostas de Mário às nossas inquietações eram ruas que se abriam, perspectivas, ideias, tudo novo, provocante. Uma coisa é a ideia literária no papel, abstração mais ou menos atraente; outra é o movimento corporal, a ideia que agita os braços, ri, careteia súbito fica séria, crava sua lâmina na gente, pela voz e pelo gesto. Dessa viagem a Minas sairam os poemas pau-brasil de Oswald, o "Noturno de Belo Horizonte", de Mário, as cores coloniais, tão subversivas para o tempo, de Tarsila, alguns poemas de Cendrars. Para nós - para mim - seria a descoberta de Mário de Andrade, logo 
explorada em profundidade nas cartas que Ihe mandávamos, e que ele respondia com a extensão e a força de um rio ordenado... (ANDRADE, C., 1968).

Abaixo estão reproduzidos alguns trechos da primeira carta enviada por Mário de Andrade a Carlos Drummond, datada de 10 de novembro de 1924. Neles é possivel vislumbrar uma parte da força e da extensão, como disse o poeta mineiro, da correspondência de Mário de Andrade. Além da beleza e da urgência das palavras, os trechos também interessam na medida em que revelam o modo como Mário de Andrade compreendia o projeto de Brasil ao qual intimamente se engajara:

Veja bem, eu não ataco nem nego a erudição e a civilização, como fez o Osvaldo num momento de erro, ao contrário respeito-as e cá tenho também (comedidamente, muito comedidamente) as minhas fichinhas de leitura. Mas vivo tudo. [...] Você é uma sólida inteligência e já muito bem mobiliada... à francesa. Com toda a abundância do meu coração eu lhe digo que isso é uma pena. Eu sofro com isso. Carlos, devote-se ao Brasil, junto comigo. Apesar de todo o ceticismo, apesar de todo o pessimismo e apesar de todo o século XIX, seja ingênuo, seja bobo, mas acredite que um sacrifício é lindo. 0 natural da mocidade é crer e muitos moços não creem. Que horror! Veja os moços modernos da Alemanha, da Inglaterra, da França, dos Estados Unidos, de toda a parte: eles creem, Carlos, e talvez sem que o façam conscientemente, se sacrificam. Nós temos que dar ao Brasil o que ele não tem e que por isso até agora não viveu, nós temos que dar uma alma ao Brasil e para isso todo sacrifício é grandioso, é sublime. E nos dá felicidade. [...] Eu não amo o Brasil espiritualmente mais que a França ou a Cochinchina. Mas é no Brasil que me acontece viver e agora só no Brasil eu penso e por ele tudo sacrifiquei. A língua que escrevo, as ilusões que prezo, os modernismos que faço são pro Brasil. [...] Os gênios nacionais não são de geração espontânea. Eles nascem porque um amontoado de sacrificios humanos anteriores lhes preparou a altitude necessária de onde podem descortinar e revelar uma nação. Que me importa que a minha obra não fique? É uma vaidade idiota pensar em ficar, principalmente quando não se sente dentro do corpo aquela fatalidade inelutável que move a mão dos gênios. 0 importante não é ficar, é viver. Eu vivo. E vocês não vivem porque são uns despaisados e não têm a coragem suficiente pra serem vocês. E preciso que vocês se ajuntem a nós ou com este delírio religioso que é meu, do Osvaldo, de Tarsila ou com a clara serenidade e deliciosa flexibilidade do pessoal do Rio, Graça, Ronald. De qualquer jeito porque não se trata de formar escola com um mestrão na frente. Trata-se de ser. E vocês por enquanto ainda não são (ANDRADE, M., 2015, p. 16-22). 
Aqui, mais uma vez, está clara a intensidade do projeto de brasilidade de Mário de Andrade, Tarsila do Amaral e Oswald de Andrade. Como disse Gilda de Mello e Souza, a entrega de Mário de Andrade à busca da identidade brasileira diz respeito ao desejo de encontrar também a própria identidade. 0 significado de ser Mário de Andrade, sendo brasileiro, já que "é no Brasil que me acontece viver". Apesar das diferenças entre a sua postura e a de Oswald de Andrade, Mário reconhece que há uma atitude que os une. É ainda evidente na carta a noção de construção histórica da brasilidade. Um corpo não se faz do dia para a noite. Que dirá uma alma, que tem matéria mais sutil. Não é possível dar uma alma ao Brasil, como pede Mário de Andrade a Carlos Drummond, sem que haja a doação do próprio corpo, o sacrificio. E é claro que nesse processo, afinal, ritualístico, a roupa participa ativamente.

\section{Considerações finais}

Se reconhecemos que o projeto nacionalista dos modernistas é abrangente, não se restringe a um projeto estético, como diz Telê Porto Ancona Lopez, as escolhas vestimentares dessas três figuras do modernismo brasileiro estão atravessadas e imbuídas pelo projeto ideológico, que pretende amplitude em suas ações. $A$ análise do vestuário usado pelos três - especificamente ao longo da década de 1920 - contribui para a reflexão sobre o modernismo brasileiro, indicando novos desdobramentos sobre o projeto estético do movimento, que também foi um projeto político e ideológico, situado na conjunção de vanguarda e nacionalismo.

0 grupo modernista - de São Paulo, do Rio de Janeiro, do Recife e de inúmeras outras cidades do Brasil - compreende uma gama de artistas escritores, artistas plásticos, músicos - e seus parentes, amigos, colaboradores e incentivadores, formando um verdadeiro entourage. No intuito de alcançar o significado dos trajes de Mário de Andrade, Tarsila do Amaral e Oswald de Andrade para os círculos sociais que frequentavam, no Brasil e no estrangeiro, é necessário estabelecer os padrões de vestuário com os quais o trio convivia, já que os três foram habitués de diversos ambientes e cidades ao longo dos anos 1920. Dispostos lado a lado o padrão do vestuário e a realização da norma (BARTHES, 2005), é possivel analisar como o guarda-roupa modernista se relaciona com os padrões vestimentares brasileiro e europeu. Aqui, a aparência é compreendida como fato social e estético. Assim, as aparências de Mário de Andrade, Tarsila do Amaral e Oswald de Andrade devem estar inseridas no contexto histórico de elaboração da brasilidade modernista e, também, devem ser cotejadas com o projeto estético elaborado pelos três, cujo resultado está vincado nas obras de arte e literárias. Seus trajes têm que ser colocados em perspectiva com o resultado artístico de suas produções, inseridas na estética do modernismo brasileiro da década de 1920.

0 vestuário é, conscientemente ou não, uma maneira singular de elaboração da identidade, seja ela individual ou coletiva. Por mais que seja 
dificil medir o grau de intencionalidade de Mário de Andrade, Tarsila do Amaral e Oswald de Andrade em suas escolhas vestimentares, quer dizer, se de maneira programática os três investiram na construção de suas aparências como um modo de expressão estética e artística que fosse incluído no projeto ideológico de brasilidade modernista, é nítido que suas aparências e suas roupas expressam - ou, mais ainda, corroboram e ajudam a construir - o projeto de brasilidade modernista, com todas as suas complexidades, limites e contradições, forjado por essas figuras emblemáticas da história da cultura brasileira. As práticas vestimentares são modos de tecer discursos que atuam na composição de nossas figuras públicas e privadas. Nesse sentido, a aparência e o vestuário desses três personagens do nosso modernismo participam da divulgação de uma estética moderna e brasileira que eles desejavam construir e transmitir, relacionada ao projeto de construção de uma identidade nacional.

Os corpos dos artistas estão implicados na produção das obras, na elaboração dos projetos. 0 corpo é o suporte, dos gestos, da aparência, do vestuário, incluídos na rede de narrativas tecidas em torno da questão da identidade nacional. Por meio do cruzamento de registros visuais e escritos, e também de algumas peças que foram preservadas, os corpos de Mário de Andrade, Tarsila do Amaral e Oswald de Andrade aparecem, mesmo que de modo fragmentário.

Recebido em: 8-07-2018

Aprovado em: 7-08-2018

\section{NOTAS}

${ }^{1} 0$ conceito de aparência utilizado é aquele definido por Michèle Pagès-Delon (1989) na obra Le corps et ses apparences: l'envers du look, conforme será discutido adiante.

${ }^{2} 0$ modernismo brasileiro foi um movimento amplo, de várias fases, com uma atuação que engloba diversos campos da arte e da cultura, como literatura, artes plásticas, música, arquitetura. A primeira geração do modernismo brasileiro, cuja crítica indica como figuras proeminentes Mário de Andrade, Tarsila do Amaral e Oswald de Andrade, entre outras, é fortemente marcada pela influência das vanguardas europeias e a busca de uma identidade nacional. Não se pode afirmar que tenha havido um modernismo brasileiro, nem mesmo uma única primeira geração de nosso modernismo, pois houve iniciativas de renovação e investigação da identidade nacional em diferentes cidades do Brasil, a partir de diversos grupos de artistas, que remontam ao final do século XIX (JARDIM, 2016). Entretanto é preciso admitir que as acões dos modernistas de São Paulo, especialmente Mário de Andrade e Oswald de Andrade, no campo da literatura, e Tarsila do Amaral e Anita Malfatti, nas artes plásticas, são reconhecidas nacionalmente, seja porque historicamente a crítica atribui a essas figuras um lugar de protagonismo, seja porque - e principalmente Mário de Andrade - elas procuraram elaborar um projeto amplo, que objetivava gerar transformações no plano cultural do pais. 0 olhar crítico sobre o modernismo brasileiro obriga-nos a afirmar a existência de "um modernismo composto de muitos modernismos, com seus pontos de comunhão e dissidências", como afirma Eduardo Coelho na apresentação da nova edição do livro de Eduardo Jardim (JARDIM, 2016, p. 15). Mas, para o objetivo deste artigo, emprega-se aqui o termo modernismo brasileiro, com a consciência de que esta é uma expressão ao mesmo tempo redutora - posto que há vários modernismos - e abrangente - já que amplifica as ações do modernismo paulista.

${ }^{3}$ Segundo Chaney (apud MENESES, 2002, p. 151): a visualidade é "um conjunto de discursos e práticas que constituem distintas formas de experiência visual em circunstâncias historicamente específicas". 
${ }^{4}$ Mário de Andrade (9/10/1893 - 25/2/1945), Tarsila do Amaral (1/9/1886 - 17/1/1973) e Oswald de Andrade (11/1/1890 - 22/10/1954), os três nascidos no estado de São Paulo, foram figuras importantes do modernismo brasileiro. Mário de Andrade e Oswald de Andrade, poetas, conheceram-se em 1917, como conta Oswald de Andrade em sua autobiografia Um homem sem profissão: "Como repórter, vou a uma festa no Conservatório Dramático e Musical. 0 Dr. Sorriso que é o Elói Chaves, Secretário da Justiça, faz ali uma conferência de propaganda dos Aliados. Quem o saúda é um aluno alto, mulato, de dentuça aberta e de óculos. Chama-se Mário de Andrade. Faz um discurso que me parece assombroso. Corro ao palco para arrancar-lhe das mãos o original que publicarei no Jornal do comércio. Um outro repórter, creio que d'0 Estado, atraca-se comigo para obter as laudas. Bato-o e fico com o discurso. Mário, lisonjeado, torna-se meu amigo" (ANDRADE, 0., 1976, p. 105). Em fevereiro de 1922 realiza-se, no Teatro Municipal de São Paulo, a Semana de Arte Moderna, festival com intuito renovador que contou com uma exposição de artes plásticas, além de sessões literárias e musicais. Mário de Andrade e Oswald de Andrade participaram ativamente da Semana de Arte Moderna. Tarsila do Amaral morava em Paris desde junho de 1920, mas estava a par das agitações culturais de São Paulo por meio de correspondência trocada com a também pintora Anita Malfatti. Em junho de 1922, Tarsila do Amaral retorna ao Brasil, e em julho, Anita Malfatti apresenta-a aos amigos Mário de Andrade, Oswald de Andrade e Menotti Del Picchia, todos escritores. Juntos, Anita Malfatti, Tarsila do Amaral, Mário de Andrade, Oswald de Andrade e Menotti Del Picchia formaram o chamado Grupo dos Cinco, "grupo de doidos em disparada por toda a parte no Cadillac verde de Oswald", como conta a própria Tarsila do Amaral em depoimento a Aracy Amaral publicado no livro Tarsila: sua obra e seu tempo (AMARAL, 2010, p. 66). Tarsila do Amaral e Oswald de Andrade começaram a namorar em setembro de 1922.

${ }^{5}$ A expressão "forma vestimentar" foi utilizada por Maria Cristina Volpi em sua tese de doutorado (VOLPI, 2018). Diz a autora: "Optei por empregar o termo 'formas vestimentares' para me referir às práticas encontradas nesse estudo, o qual foi tomado de empréstimo de Denise Pop-Câmpeanu - mestre de conferências na Ecole de Hautes Etudes em Sciences Sociales (EHESS) nos anos 1990. Como etnóloga e semioticista, Pop-Câmpeanu articulava os aspectos simbólicos, comunicacionais, materiais e tecnológicos de um conjunto de peças de vestuário de um grupo social no tempo e no espaço. Mais do que refletir a moda de um periodo, o aspecto e a ordenação dessas formas vestimentares constituem a expressão individual e as escolhas simbólicas de um grupo" (VOLPI, 2018, p. 14).

${ }^{6}$ Foram consultados os dicionários Bluteau (1728), Silva (1789), Freire (1954) e Houaiss; Villar (2009).

A pesquisa documental acontece, majoritariamente, nas seguintes instituições: Fundação Casa de Rui Barbosa (Rio de Janeiro-RJ), Museu Nacional de Belas Artes (Rio de Janeiro-RJ), Casa Mário de Andrade (São Paulo-SP), Instituto de Estudos Brasileiros da USP (São Paulo-SP), Museu da Imagem e do Som de São Paulo, Museu Paulista da USP (São Paulo-SP), Pinacoteca do Estado de São Paulo, Centro de Documentação Alexandre Eulálio da Unicamp (Campinas-SP).

${ }^{8}$ Paul Poiret (20/4/1879 - 30/4/1944), Le Magnifique, foi um costureiro francês que teve atuação intensa no cenário da alta-costura parisiense nas primeiras duas décadas do século XX. Conhecido por suas inovações em relação à silhueta feminina - ele foi um dos responsáveis, ao lado de Lucile (Lady Duff Gordon) e Madeleine Vionnet, pela proposta de liberacão do uso do espartilho - - Paul Poiret foi o primeiro costureiro a agregar outras linhas de produto à sua maison, como perfumes e objetos. As criações luxuosas da Maison Poiret foram pautadas naquilo que os europeus e os norte-americanos costumam chamar de "exotismos" e "orientalismos", cujo resultado material são cores vivas e contrastantes (o que não era o hábito no início do século XX); franjas; modelagens amplas (KODA; BOLTON, 2008; MENDES; HAYE, 2003).

${ }^{9}$ No original: "entendue comme le corps et les objets portés par lui, le corps, sa présentation, sa représentation, c'est-à-dire, l'ensemble des caractères physiques constants ou variant lentement (poids, taille, traits du visage), d'attitudes corporelles (postures, expressions, mimiques) et d'attributs (habits, coiffures, maquillages, accessoires). [...] Toute interaction sociale est, en premier lieu, corporelle et réglée par une série de rituels qui, prenant souvent le corps pour support, forment la trame de "l'être ensemble", de la socialité". A tradução é de nossa autoria.

${ }^{10}$ No original: "Indices d'une condition sociale déterminée par les informations qu'elles livrent, les apparences corporelles sont construites par toutes une série de pratiques et de représentations". A tradução é de nossa autoria.

${ }^{11}$ No original: "Nous entendons ici pratiques un ensemble d'activités, de conduites, d'actions mettant en jeu un certain nombre de moyens, d'outils et de techniques et visant une ou des finalités particulières. Les apparences corporelles sont le résultat de la production d'une combinaison de pratiques: vestimentaires, d'hygiène, sportives ou para-sportives, d'alimentation, de marquage et de paraître." A tradução é de nossa autoria

${ }^{12}$ De acordo com o Dicionário Aulete Digital, cachaço pode significar a carne que se tira da parte posterior do pescoço dos bovinos; pescoço grosso ou largo e, também, de modo figurado, arrogância, presunção, soberba (nota de nossa autoria).

13 "Na cidade o homem elegante usava luvas de couro - cape - pelica ou doeskin nas cores bronze, cinza ou preto, com 3 fileiras de pontos nas costas, fechadas por 1 ou 2 botões ou dome snap fastners. À noite, suede, pelica ou luvas de tecido em branco, bege ou cinza. As gauntlets eram usadas apenas para dirigir. Já o uso das luvas para esporte - sky e golf - cresceram. Em 1920 e 30 as luvas ganharam uma essência prática, funcional, usadas para a protecão, conforto ou para roupas formais. A partir de 1950, as luvas para homens eram sempre lisas, de couro cape, em cores escuras, luvas de natural hogskin ou pele de porco com costura à mão. De qualquer modo, quando a informalidade no vestir passou a ser mais admirada do que a formalidade, foi inevitável que os dois acessórios mais caros - luvas e chapéus - tivessem menos importância que outras prioridades" (ANDRADE, R., 1998, p. 12).

${ }^{14}$ As calçadeiras de madeira com que Mário de Andrade mantinha seus sapatos podem ser vistas hoje na Casa Mário de Andrade, logo na entrada, numa das estantes com porta de vidro desenhadas pelo poeta (nota de nossa autoria).

${ }^{15}$ Foram consultadas as seguintes obras de referência: Terminologia do vestuário (ANHESINI; QUEIROZ, 1996), Histoire du costume en Occident (BOUCHER, 1969, o original em francês e a tradução publicada no Brasil em 2010), Enciclopédia da moda (CALLAN, 2007)), Dictionnaire international de la mode (REMAURY; KAMITSIS, 2004).

${ }^{16}$ Gilda de Mello e Souza, em solteira Gilda de Moraes Rocha, era bisneta de Joaquim de Almeida Leite Moraes, avô materno de Mário de Andrade (de acordo com CASTRO, 2016, p. 46). 
${ }^{17} 0$ depoimento de Gilda de Mello e Souza sobre Mário de Andrade está disponível no endereço eletrônico https://vimeo.com/140019033 (SOUZA, 1992). Foi publicado nos livros Eu sou trezentos, eu sou trezentos e cincoenta: Mário de Andrade visto por seus contemporâneos, organizado por Telê Porto Ancona Lopez (2008) e A palavra afiada, de Gilda de Mello e Souza (2014).

${ }^{18} \mathrm{O}$ brogue é um "sapato resistente originário da Escócia e da Irlanda, como peça inteiriça de couro cru, amarrado por um cordão. 0 brogue moderno é um sapato de amarrar, com salto baixo. Feito de couro costurado, tem um desenho perfurado" (CALLAN, 2007, p. 56). "Em geral com estampas decorativas perfuradas e às vezes wingtip (biqueira em forma de asa). É muito usado para a prática de esportes, como o golfe" (NEWMAN, 2011, p. 34).

${ }^{19}$ Carlos Drummond de Andrade (31/10/1902 - 17/8/1987) foi um poeta e contista brasileiro, nascido em Itabira, Minas Gerais. Normalmente relacionado à segunda geração do modernismo, foi grande amigo de Mário de Andrade, com quem trocou correspondência a partir de 1924 até 1945, ano da morte de Mário.

\section{REFERÊNCIAS}

AMARAL, Aracy. Tarsila: sua obra e seu tempo. 4. ed. São Paulo: Editora 34; Edusp, 2010.

ANHESINI, Célia M. J.; QUEIROZ, Fernanda. Terminologia do vestuário: português; espanholportuguês; inglês-português; francês-português. São Paulo: Escola SENAI Eng. ${ }^{\circ}$ Adriano José Marchini - Centro Nacional de Tecnologia em Vestuário, 1996.

ANDRADE, Carlos Drummond de. A caravana paulista. Correio da Manhã, Rio de Janeiro, 22 maio 1968.

ANDRADE, Mário. A imagem de Mário: fotobiografia de Mário de Andrade. Introdução Telê Ancona Lopez. Texto critico Ferreira Gullar. Rio de Janeiro: Edições Alumbramento; Livroarte Editora, 1998.

A lição do amigo: cartas de Mário de Andrade a Carlos Drummond de Andrade. Anotadas pelo destinatário. São Paulo: Companhia das Letras, 2015.

ANDRADE, Oswald. Um homem sem profissão. Rio de Janeiro: Civilização Brasileira, 1976. Obras Completas, v. 9.

ANDRADE, Rita Morais de. Coleção de luvas. Projeto de estágio (orientação Teresa Cristina Toledo de Paula) - Setor de Conservação de Têxteis Históricos, Museu Paulista, Universidade de São Paulo, São Paulo, 1998.

BARTHES, Roland. Fragmentos de um discurso amoroso. Tradução Márcia Valéria Martinez de Aguiar. São Paulo: Martins Fontes, 2003.

História e sociologia do vestuário. In: Inéditos, vol. 3 - imagem e moda. Tradução Ivone Castilho Benedetti. São Paulo: Martins Fontes, 2005, p. 257-281. Fontes, 2009.

Sistema da moda. Tradução Ivone Castilho Benedetti. São Paulo: Editora WMF Martins

BLUTEAU, Raphael. Vocabulario Portuguez \&t Latino, 1728. Disponível em: http://dicionarios.bbm. usp.br/dicionario. Acesso em: 1 maio 2017.

BOUCHER, François. Histoire du costume en Occident de l'antiquité a nos jours. Paris: Flammarion, 1969.

História do vestuário no Ocidente: das origens aos nossos dias. Tradução André Telles. São Paulo: Cosac Naify, 2010.

BURGELIN, Olivier. Vestuário. Tradução Maria Bragança. Enciclopédia Einaudi, volume 32. Soma/ psique - corpo. Lisboa: Imprensa Nacional - Casa da Moeda, 1995, p. 337-363.

CALLAN, Georgina O'Hara. Enciclopédia da moda: de 1840 à década de 90 . Verbetes brasileiros Cynthia Garcia. Tradução Glória Maria de Mello Carvalho; Maria Ignez França. São Paulo: Companhia das Letras, 2007.

CANDIDO, Antonio. Vários escritos. 4. ed. reorganizada pelo autor. Rio de Janeiro: Ouro sobre Azul; São Paulo: Duas Cidades, 2004.

CASTRO, Moacir Werneck de. Mário de Andrade: exílio no Rio. 2. ed. Belo Horizonte: Autêntica, 2016.

DIDI-HUBERMAN, Georges. 0 que vemos, o que nos olha. Tradução Paulo Neves. 2. ed. São Paulo: Editora 34, 2014. 
FREIRE, Laudelino. Grande e novisssimo dicionário da língua portuguesa. 2. ed. Rio de Janeiro: José Olympio, 1954.

HOUAISS, Antônio; VILLAR, Mauro de Salles. Dicionário Houaiss da língua portuguesa. 1. ed. Rio de Janeiro: Objetiva, 2009.

JARDIM, Eduardo. A brasilidade modernista: sua dimensão filosófica. Edição revista e atualizada. Rio de Janeiro: Ed. PUC-Rio; Ponteio, 2016.

KODA, Harold; BOLTON, Andrew. Paul Poiret (1879-1944). In: Heilbrunn Timeline of Art History. New York: The Metropolitan Museum of Art, 2008. Disponivel em: http://www.metmuseum.org./ toah/hd/poir/hd_poir.htm. Acesso em: 20 de agosto 2018.

LOPEZ, Telê Porto Ancona. Introdução. In: ANDRADE, Mário. 0 turista aprendiz. Estabelecimento do texto, introdução e notas de Telê Porto Ancona Lopez. Belo Horizonte: Itatiaia, 2002. Obras de Mário de Andrade, v. 20.

. (Org.). Eu sou trezentos, eu sou trezentos e cincoenta: Mário de Andrade visto por seus contemporâneos. Rio de Janeiro: Agir, 2008.

MENDES, Valerie; HAYE, Amy de la. A moda do século XX. Tradução Luis Carlos Borges. Revisão técnica José Luiz Andrade. São Paulo: Martins Fontes, 2003.

MENESES, Ulpiano Bezerra de. A fotografia como documento - Robert Capa e o miliciano abatido na Espanha: sugestões para um estudo histórico. Tempo [on-line], Rio de Janeiro, n. 14, p. 131-151, 2002. Disponivel em: http://www.redalyc.org/articulo.oa?id=167018094007. Acesso em: 22 maio 2017.

NEWMAN, Alex. Dicionário ilustrado moda de A a Z. Ilustrações Zakee Shariff. Tradução Ana Carolina Mesquita. São Paulo: Publifolha, 2011.

NAVA, Pedro. Beira-mar. São Paulo: Companhia das Letras, 2013.

PAGÉS-DELON, Michèle. Le corps et ses apparences: l'envers du look. Paris: L'Harmattan, 1989.

REMAURY, Bruno; KAMITSIS, Lydia. (Sur la direction de). Dictionnaire international de la mode. Paris: Éditions du Regard, 2004.

SILVA, Antonio de Moraes. Diccionario da lingua portugueza, 1789. Disponivel em: http:// dicionarios.bbm.usp.br/dicionario. Acesso em: 1 maio 2017.

SOUZA, Gilda de Mello e. Depoimento sobre Mário de Andrade. Centro Cultural São Paulo, 1992. Disponivel em: https://vimeo.com/140019033. Acesso em: 10 junho 2018.

. 0 espírito das roupas: a moda no século dezenove. 5. reimpressão. São Paulo: Companhia das Letras, 2005 Azul, 2014.

A palavra afiada. Organização Walnice Nogueira Galvão. 1. ed. Rio de Janeiro: Ouro sobre

VOLPI, Maria Cristina. As roupas pelo avesso: cultura material e história social do vestuário. In: COLÓQUIO DE MODA, 9., 2013, Fortaleza. Anais... São Paulo: Abepem, 2013. Disponível em: http:// www.coloquiomoda.com.br/anais/Coloquio\%20de\%20Moda\%20-\%202013/ARTIGOS-DE-GT/ Artigo-GT-Moda-Cultura-e-Historicidade/As-roupas-pelo-avesso-cultura-material-e-historiasocial-do-vestuario.pdf. Acesso em: 13 abril 2017.

. Modos masculinos de vestir na Belle Époque carioca. In: BONADIO, Maria Claudia; SIMILI, Ivana Guilherme. (Org.). Histórias do vestir masculino: narrativas de moda, beleza, elegância. Maringá: Eduem, 2017, p. 17-34.

Estilo urbano: modos de vestir na primeira metade do século XX no Rio de Janeiro. São Paulo: Estação das Letras e Cores, 2018. 